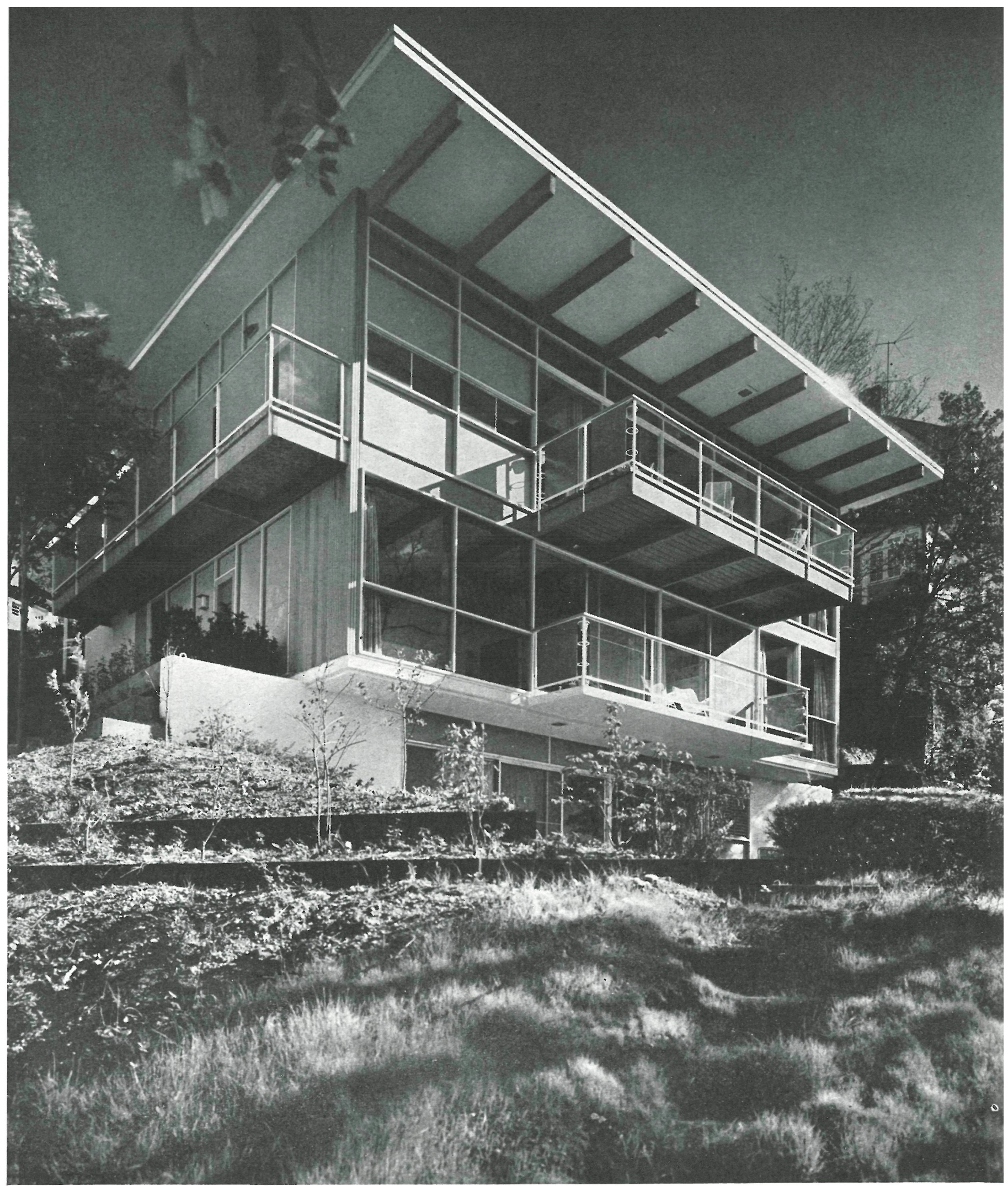

$161 \cdot 79$

\title{
vivienda en long Island
}

DANIEL SCHWARTZMAN, arquitecto 


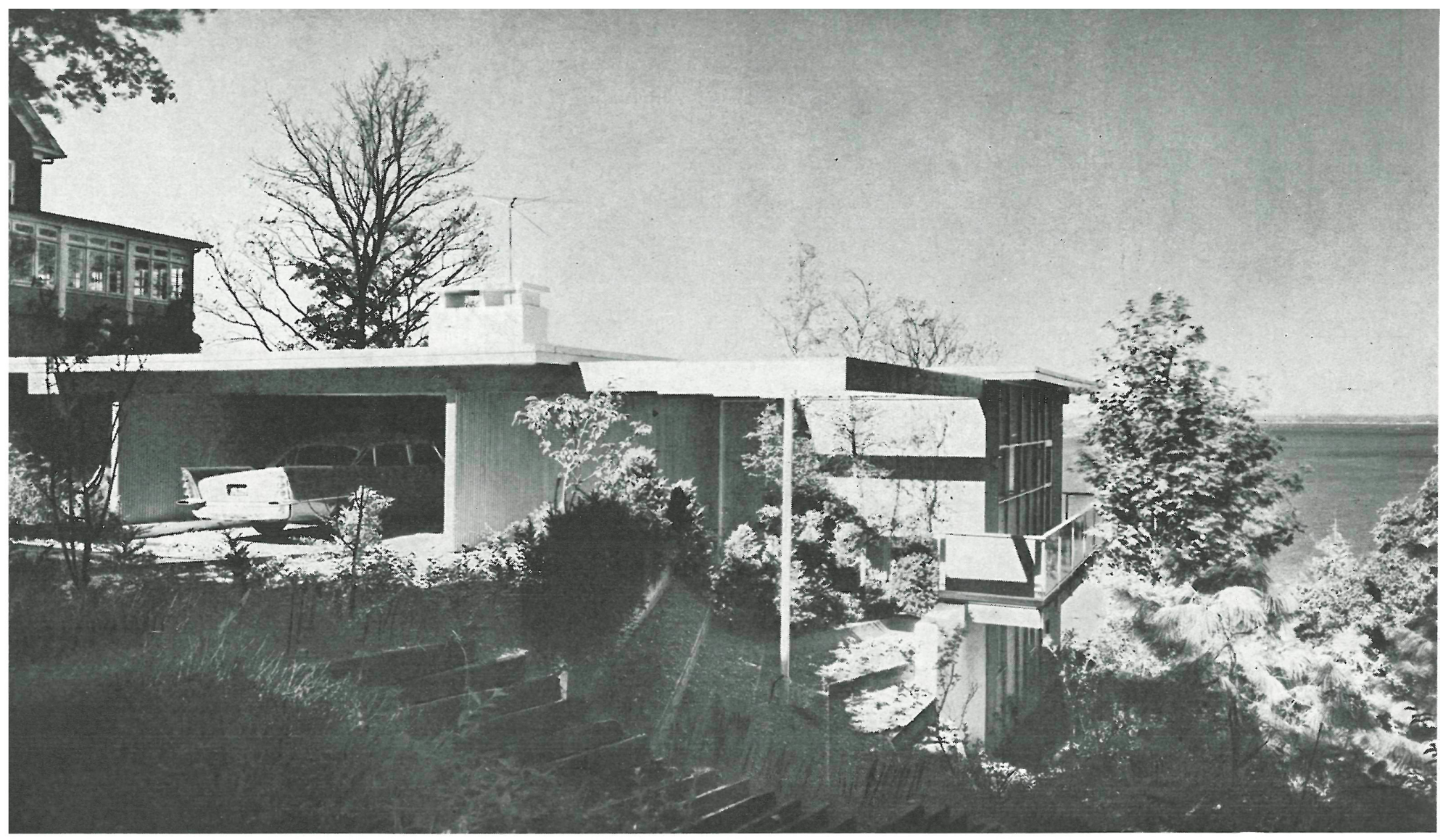

El arquitecto ha construído su propia casa sobre un terreno de gran pendiente que desciende fuertemente hacia el mar. Así, pues, ciñéndose a la topografía, se ha conseguido una vivienda en tres alturas, todas ellas con una orientación fundamental noroeste, con grandes y diáfanas fachadas que permiten a la vista extenderse sobre la lámina azul, salpicada por las blancas velas de las embarcaciones deportivas y de recreo. El panorama que se divisa desde los volados balcones, se prolonga hasta la playa de Sands Point, y alcanza, a lo lejos, la línea costera del Condado de Westchester y de Connecticut.

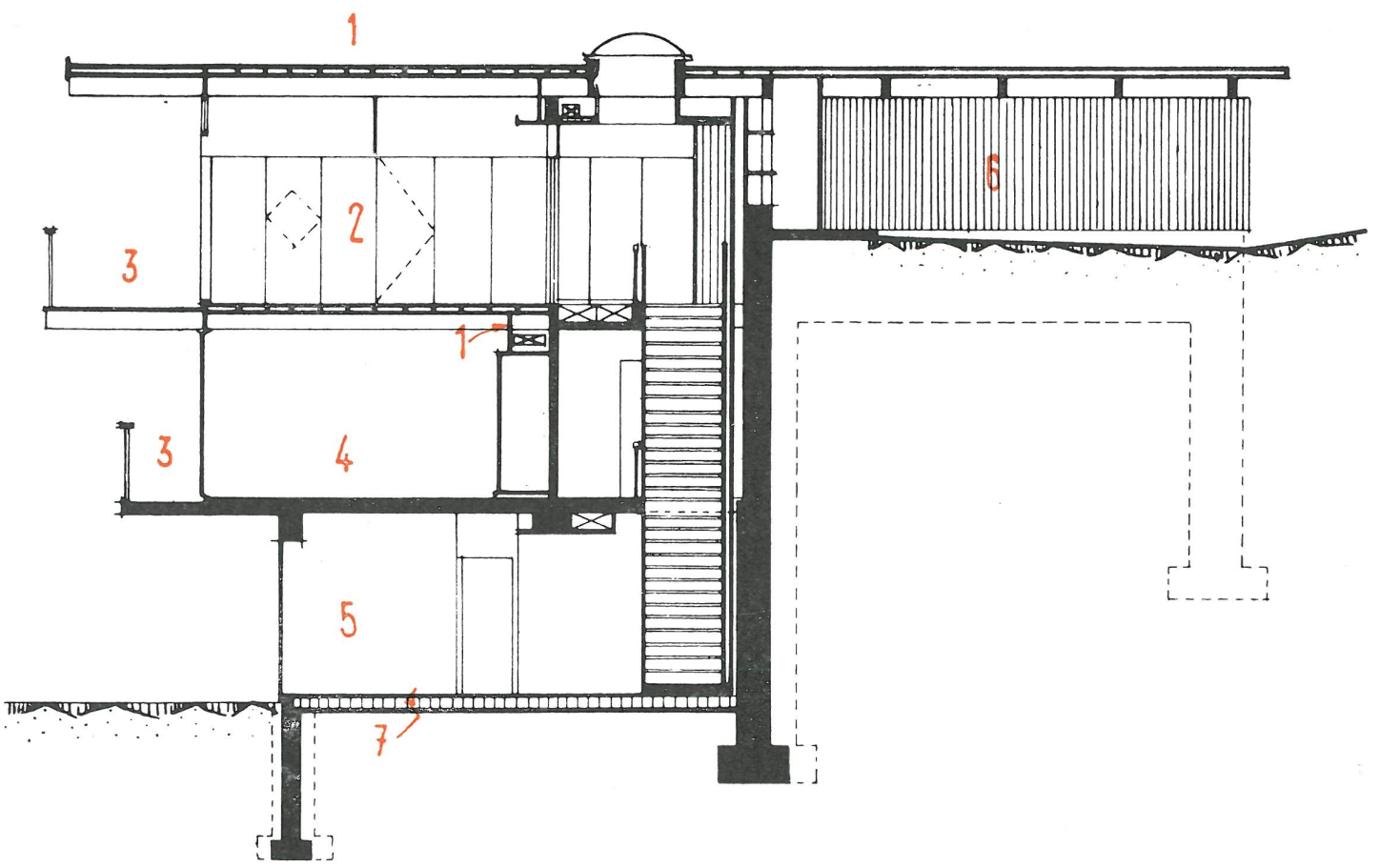

1. Paneles radiantes. 2. Estar-3. Balcón.4. Dormitorios.--5. Estudio.-6. Garaje.-7. Losetas radiantes. 


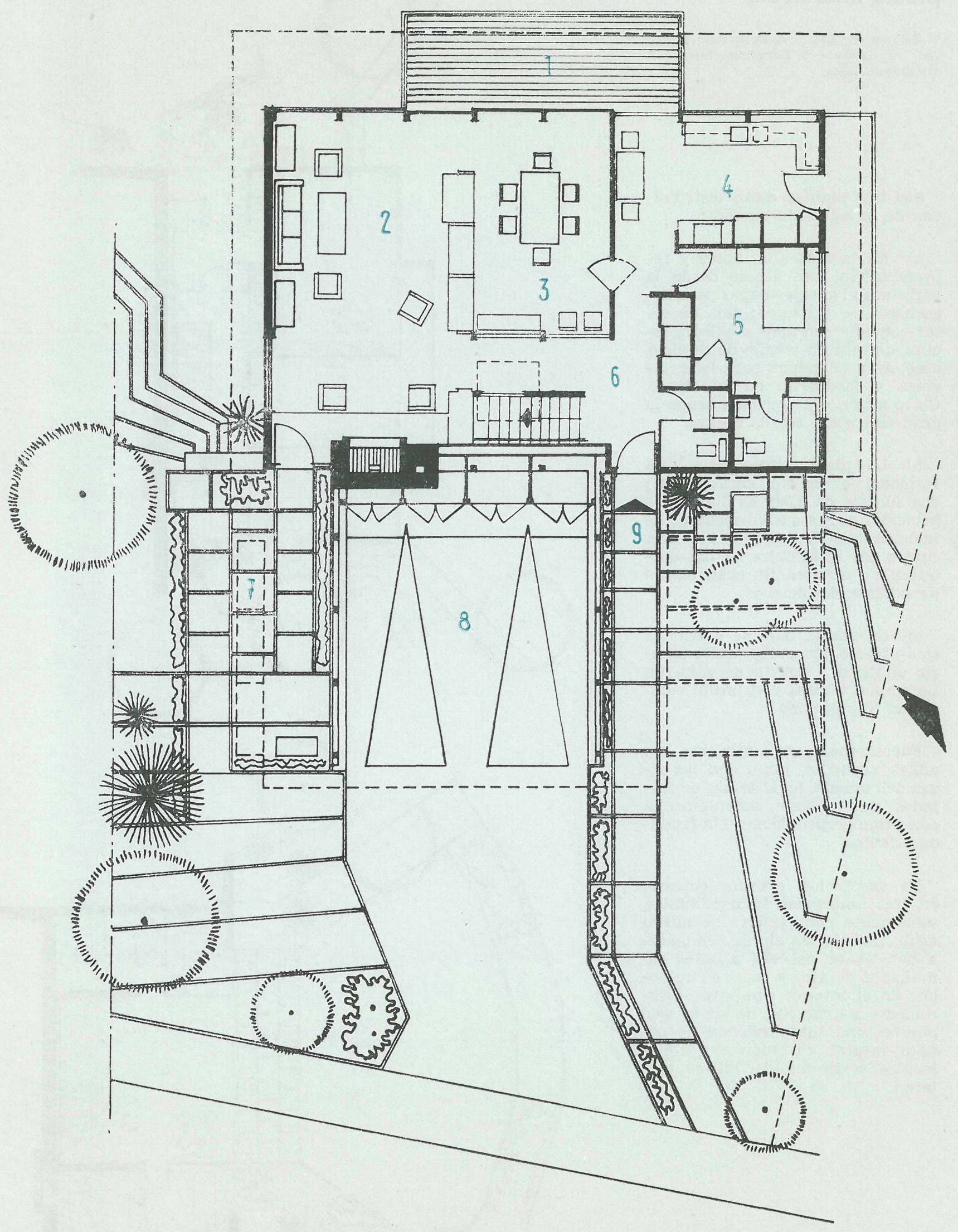

planta principal

1. Balcón del estar-comedor.-2. Estar.-3. Comedor.

4. Cocina.-5. Dormitorio servicio.-6. Vestíbulo.-

7. Terraza del estar.-8. Garaje.-9. Entrada. 


\section{planta intermedia}

1. Terraza.-2, Baño.-3. Dormitorio principal. - 4. Alcoba. - 5. Dormitorio hijas. - 6 . Dormitorio hijos.

Sus tres plantas están distribuídas de la siguiente manera:

a) En la más alta, noble y representativa, con acceso desde la carretera al garaje-capaz para dos coches-, se disponen: sala de estar-comedor con amplio balcón, cocina, dormitorio y baño de servicio, aseo, gran chimenea para leña, terraza y jardinería en pendiente. Cinco módulos de fachada ocupa la gran estancia y tres la cocina.

b) La planta intermedia está formada por los tres dormitorios y dos cuartos de aseo. El dormitorio principal ocupa cuatro módulos de fachada, distribuyéndose los otros cuatro por igual entre los dos dormitorios restantes. Un gran balcón da salida a dos de ellos.

c) La planta baja se destina a sala-estudio, lavadero, cuarto oscuro, almacén y cuarto de calderas. La amplia terraza y el jardín completan el programa.

Fuertes muros de contención, con aletas, soportan, junto con las vigas de fachada, los sistemas de forjados que vuelan valientemente, con ritmo perpendicular a la fachada principal.

La decoración exterior consiste en tres materiales fundamentales, sabiamente conjugados: hormigón visto, madera de ciprés acanalada y paneles de asbesto, algunos esmaltados de azul y otros en su color. En el interior campean sinceramente las viguetas de madera de pino escuadrada, sirviendo de ornato natural, en unión de los elementos verticales, del mismo material.

\section{planta baja}

1. Lavadero.-2. Cuarto oscuro.-3. Almacén 4. Salón-estudio.-5. Patio.-6. Sala de calderas.
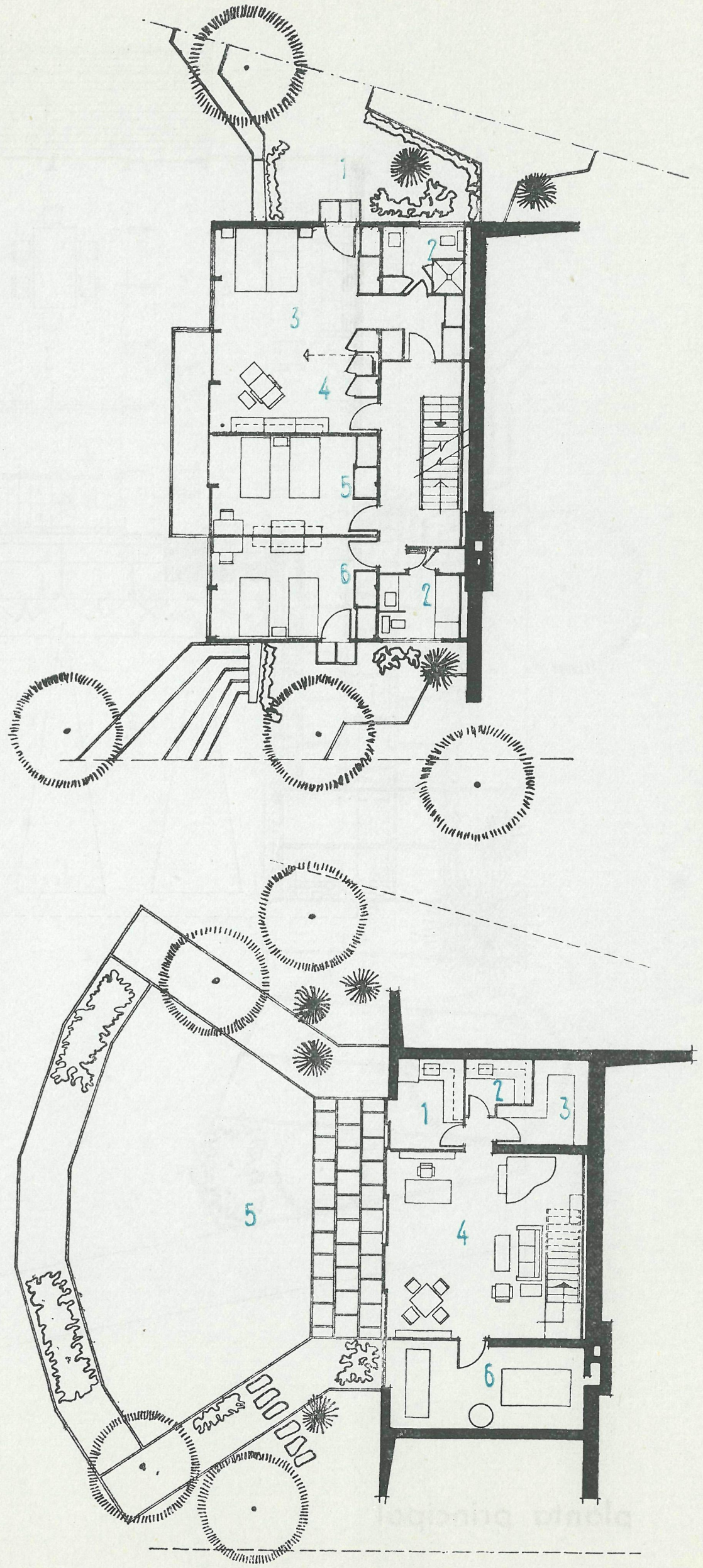
Grandes zonas acristaladas, abriéndose al horizonte, constituyen la diáfana y rítmica textura externa.

La madera de ciprés, en su color natural, ha sido, asimismo, elemento decorativo en las paredes de las habitaciones principales, mientras la tabiquería de algunas estancias se ha fabricado con tableros chapados de caoba.

El pavimento de las terrazas y paseos de entrada es de losetas de mármol granulado.
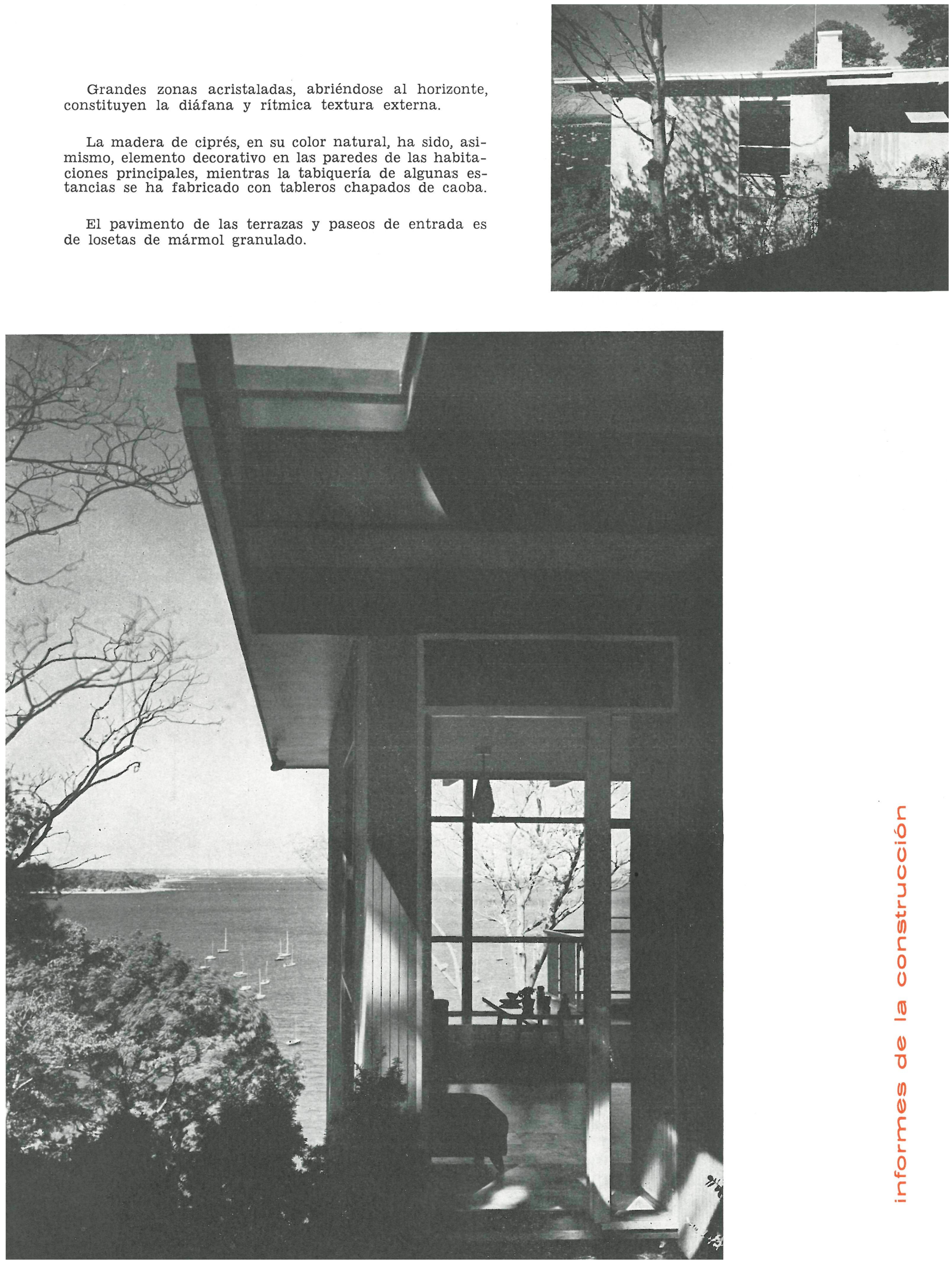


\section{interiores}

La calefacción se ha previsto mediante paneles radiantes en techos y suelos. Este mismo sistema se utilizará para refrigerar la casa.

La casa, en fin, ofrece un aspecto grato, rico y cuidadosamente construído en todas sus facetas, jugando un
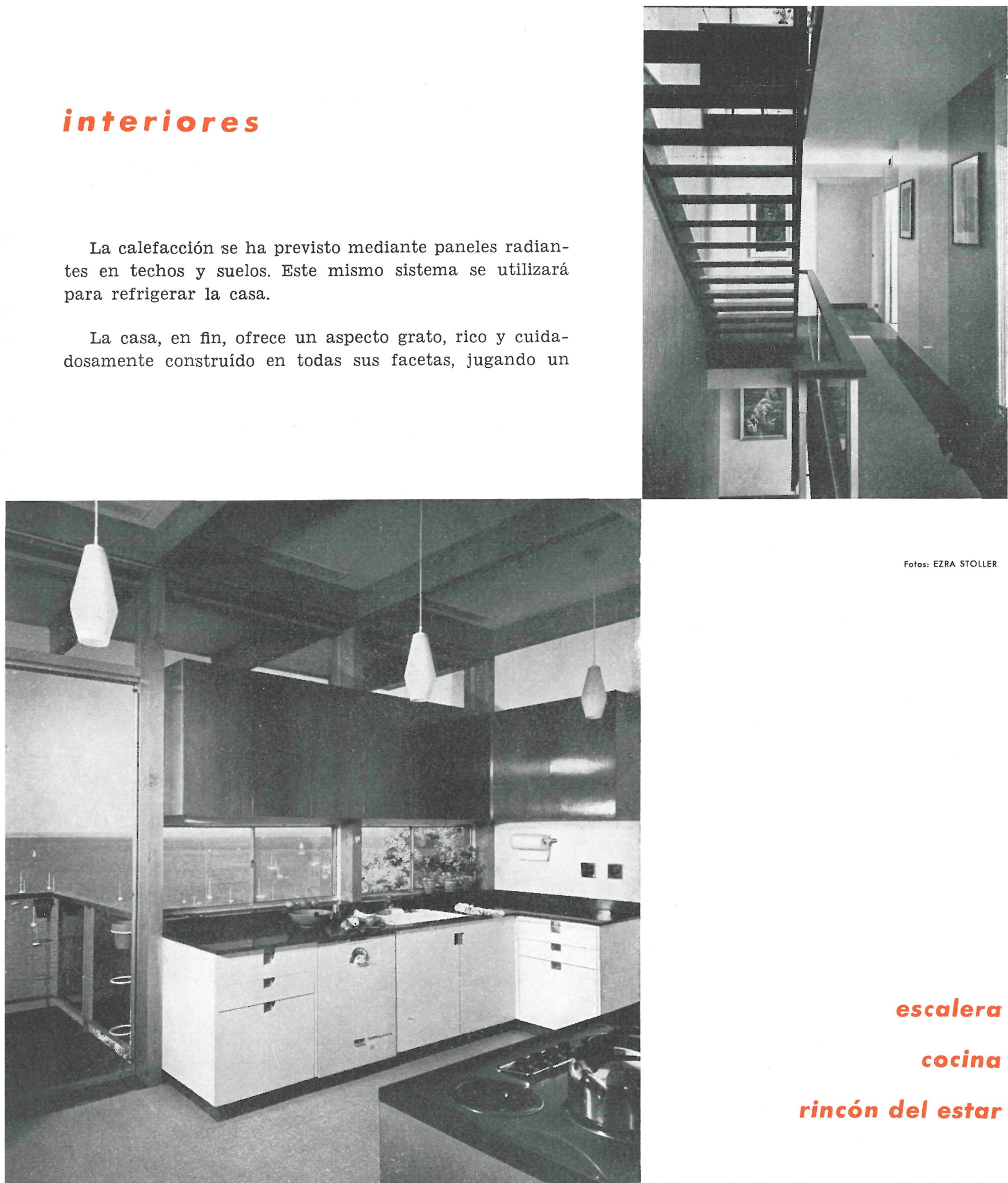

Fotos: EZRA STOLLER

escalera

cocina

rincón del estar

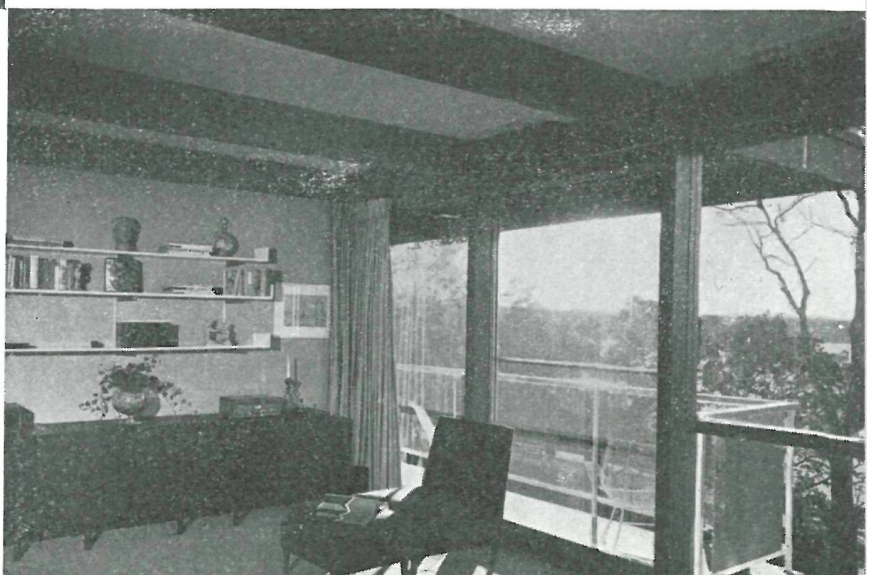

